\title{
ルーリエ系のパラメトリック絶対安定性
}

\author{
和田 光代 ${ }^{* *}$. 池田 雅夫 ${ }^{* * *} \cdot$ 太田 有三 ${ }^{* * *} \cdot$ Dragoslav D. ŠILJAK ${ }^{* * * *}$
}

\section{Parametric Absolute Stability of Lur'e Systems*}

\author{
Teruyo WAdA ${ }^{* *}$, Masao IKedA ${ }^{* * *}$, Yuzo OhtA ${ }^{* * *}$ and Dragoslav D. Šlldak ${ }^{* * * *}$
}

\begin{abstract}
The concept of parametric absolute stability of Lur'e systems is defined. It provides a mathematical framework for solving the joint problem of feasibility and stability of equilibrium states of Lur'e systems with uncertain parameters and sectorial bounded nonlinearities. This problem arises since stability may be disturbed by the change of equilibrium states which is caused by the parameter variation. In this paper, we consider a single-input single-output Lur'e system, and present Popov-type sufficient conditions for parametric absolute stability. Although the condition contains the parameters, it can be tested by computing the value sets or a family of Popov plots.
\end{abstract}

\section{1.はじめに}

動的な線形時不変部之静的な非線形部から成るフィー ドバック系は，ルーリエ系と呼ばれる。 その線形部が不 確かなパラメータを含む場合の安定性については, てれ までにあ考えられてきた1) 5). そてでは，参照入力を零 と仮定し，非線形部を零入力に対しては出力が零である あのとしている. したがって, 線形部が公称系から変化 しても平衡状態は常に原点であり，その前提のもとで議 論されている.

一方，参照入力が零でないルーリエ系では，平衡状態 は，屯はや原点ではなく，線形部のパラメータと非線形 部に依存したものとなる。 しかあ, パラメータの公称值 に対して平衡状態がただ一つであったとしてあ，パラメ 一夕が変化すると, 平衡状態は複数個存在するかあしれ ないし，あるいは，存在しないかあしれない，すなわち， システム全体の安定性が, 線形部のパラメータ変動に直 接影響されるだけでなく, パラメータ変動による平衡状 態の変化によっても変わり得る. したがって, 参照入力 とパラメータ変動による平衡状態の変化を考慮に入れた

* 原稿受付 1993 年 9 月 29 日

** 大阪府立大学 工学部 University of Osaka Prefecture ; Gakuen-cho, Sakai city, Osaka 593, JAPAN

*** 神戸大学 工学部 Kobe University ; Rokkodai-cho, Nada ward, Kobe city, Hyogo 657, JAPAN

**** サンタクララ大学 Santa Clara University; Santa Clara, CA 95053, U.S.A.

Key Words : nonlinear feedback system, Lur'e systems, robust stability, absolute stability, Popov condition.
安定解析が必要である.

本論文では，線形部に不確かなパラメータを含み，非 線形部があるセクタ条件を満たす 1 入力 1 出力ルーリエ 系に対して, 参照入力上パラメータの変動による平衡状 態の変化を考慮に入れた安定性について考える. てのよ うな平衡状態の変化を考慮に入れた安定性の概念をパラ メトリック安定性といい， ロトカ・ボルテラ方程式で記 述される生態系やサブシステムの結合からなる複合系な どを対象に研究がなされている6).

とてろで, 従来からルーリエ系の安定解析においては, 非線形部はあるセクタ条件を満たす任意のあのとして, 系の安定性を保証する絶対安定性という概念が考えられ てきた ${ }^{7)}$. 本論文であ, 非線形部は指定されたセクタ条 件を満たす任意のあのとし, 参照入力の変化や線形部の パラメータ変動のもとでの安定性をパラメトリック絶対 安定性之呼ぶことにする。 そして, ルーリエ系がパラメ トリック絶対安定であるための条件を，平衡状態の変動 の解析と, パラメータを含むポポフの安定条件によって 与える.

\section{2. 平衡状態亡安定性の変化}

ルーリエ系では, 参照入力の変化やパラメータ変動に よって平衡状態が変化し得る. 乙の平衡状態の変化のた めに, システムの動特性が変化し, 安定性む変化し得る ことを例により示す.

つぎのルーリエ系を考えよう。

$$
\dot{x}=A x+b \varphi(e), e=r-y, \quad y=c(p) x
$$


乙こに, $r$ は参照入力で区間 $[0,10]$ の值をとる定数で あり, $A, b, c$ は,

$$
\begin{aligned}
& A=\left[\begin{array}{ccc}
0 & 1 & 0 \\
0 & 0 & 1 \\
-1 & -3.5 & -3.5
\end{array}\right], \quad b=\left[\begin{array}{c}
0 \\
0 \\
0.5
\end{array}\right] \\
& c(p)=\left[\begin{array}{lll}
p & 0 & 0
\end{array}\right]
\end{aligned}
$$

であるとする：ただし， $p$ は定数パラメータで，区間 $[-0.185,2.05]$ の值をとり得るとする. また， $\varphi$ は次式 で定義される連続な非線形関数である.

$$
\varphi(e)= \begin{cases}9 e, & e \leq 1 \\ 12 e-3, & 1<e \leq \frac{65}{64} \\ 9 e+\frac{3}{64}, & \frac{65}{64}<e\end{cases}
$$

ここでは，簡単のため， $c$ にただ一つのパラメータが含 まれる場合のみを考えている。

平衡状態は,

$$
A x+b \varphi[r-c(p) x]=0
$$

の解 $x=x^{e}(r, p)$ として得られる.（2）式を代入する 之, $x^{e}(r, p)$ は,

$$
x^{e}(r, p)=\left[\begin{array}{lll}
0.5 \varphi\left[e^{e}(r, p)\right] & 0 & 0
\end{array}\right]^{\mathrm{T}}
$$

と表わされる.乙てに， $e^{e}(r, p)$ は

$$
e^{e}(r, p)=r-c(p) x^{e}(r, p)
$$

であり,

$$
r-e=0.5 p \varphi(e)
$$

の解 $e=e^{e}(r, p)$ である。(5) 式から $x^{e}(r, p)$ は $e^{e}(r, p)$ によって一意に決まり，また，逆に（6）式汃 ら $e^{e}(r, p)$ は $x^{e}(r, p)$ によって一意に決まる.

参照入力 $r$ の值によって, 三つの場合を考える.

( I ) $r=0$ の場合：パラメータ $p$ の値によらず, 原点 $x^{e}(0, p)=0$ がただ一つの平衡状態である. 乙の平衡 状態に対応する制御偏差は, $e^{e}(0, p)=0$ である. $e=$ $e^{e}(0, p)=0$ に扔いて, 非線形関数 $\varphi(e)$ は, 七ク夕 [0, 588/65] に含まれる. てのセク夕の上限とポポフの 安定条件 ${ }^{7}$

$$
\begin{array}{r}
\operatorname{Re}\left[\frac{65}{588}+\frac{0.5 p(1+j \omega)}{(j \omega)^{3}+3.5(j \omega)^{2}+3.5(j \omega)+1}\right]>0, \\
\forall \omega \in \overline{\boldsymbol{R}}_{+}
\end{array}
$$

により,すべてのパラメータ $p \in[-0.185,2.05]$ に対 して, 平衡状態 $x^{e}(0, p)=0$ は大域漸近安定である. ただし, $\overline{\boldsymbol{R}}_{+}=[0,+\infty) \cup\{+\infty\}$ である.
(II ) $r=9.7$ の場合： $p=2$ ならば, (3), (7) 式より $e^{e}(9.7,2)=0.97$ であり, 乙の点において $\varphi$ はセク夕 [0,732/73] に含まれる. 乙のとき, ポポフの安定条件 により, 平衡状態 $x^{e}(9.7,2)$ は大域漸近安定である.

$p=1.9$ ならば, $e^{e}(9.7,1.9)=251 / 248$ となり, 乙 の点に沶ける $\varphi$ の傾き $\kappa(p)$ は 12 である. 平衡状態 $x^{e}(9.7,1.9)$ の安定解析のために, $x^{e}(9.7, p)$ のまわり での線形化システム

$$
\dot{\tilde{x}}=\tilde{A}(p) \tilde{x}
$$

を考える. こてに， $\tilde{x}=x-x^{e}(9.7, p)$ ，

$$
\begin{aligned}
\tilde{A}(p) & =A-\kappa(p) b c(p) \\
& =\left[\begin{array}{ccc}
0 & 1 & 0 \\
0 & 0 & 1 \\
-(1+0.5 p \kappa(p)) & -3.5 & -3.5
\end{array}\right]
\end{aligned}
$$

である. $\tilde{A}(1.9)$ は不安定行列であるから, $x^{e}(9.7,1.9)$ は不安定である. 行列 $\tilde{A}(p)$ が不安定となったのは, $p \kappa(p)$ の増加によるあのである. しかし， $p$ は 2 から 1.9 へと減少しているため, パラメータ $p$ の值の変化が 直接 $p \kappa(p)$ を増加させたのではない. $p$ の值の変化に よって $e^{e}(9.7, p)$ が $e^{e}(9.7,2)$ から $e^{e}(9.7,1.9)$ 一移 動したために，その点に扔ける $\varphi$ の傾き $\kappa(p)$ が増加し たのが原因である.

ての例は，非線形システムに打りる安定解析では，パ ラメータ $p$ の変化に伴う平衡状態 $x^{e}(9.7, p)$ の移動を 考慮する必要性を示唆している.

（III） $r=151 / 800$ の場合： $p \in(-0.18,2.05]$ のとき には，(7) 式はただ一つの解 $e^{e}(151 / 800, p)$ をあち, 非線形関数 $\varphi$ は, $e^{e}(151 / 800, p)$ に扔いてセク夕 $[0$, $\left.k\left(e^{e}(151 / 800, p)\right)\right]$ に含まれる.ただし，

$$
k\left(e^{e}\left(\frac{151}{800}, p\right)\right)=\frac{4(1997+11025 p)}{3(294+1625 p)}
$$

である。ホポ゚フの安定条件により, 平衡状態 $x^{e}(151 / 800$, $p)=\left[0.5 \varphi\left[e^{e}(151 / 800, p)\right] 00\right]^{\mathrm{T}}$ は大域漸近安定 であることがいえる.

とてろが，(7) 式は， $p=-0.18$ のときには二つの解, $p \in(-649 / 3600,-0.18)$ に対しては三つの解, また, $p=-649 / 3600$ のときには二つの解をそれぞれあつ. すなわち， $p \in[-649 / 3600,-0.18]$ 亿対して, (5) 式の 平衡状態 $x^{e}(151 / 800, p)$ は, 一意ではなく, したがっ て, それらは大域漸近安定とはなりえない。

$p \in[-0.185,-649 / 3600)$ に対しては，(7) 式の解は, 再びただ一つとなり, それは大域漸近安定であるてとが いえる。 
このように, 平衡状態の安定性は, パラメータの変化 に伴う平衡状態の個数の変化によって左右され得る.

以上の例により, 参照入力やパラメータの変動を伴う 非線形システムのロバスト安定解析には, 平衡状態の変 化が無視できないととが分かる．乙のような例を動機と して，以下では，ルーリエ系に対するパラメトリック絶 対安定性の概念を定義しよう.

\section{3. パラメトリック絶対安定性}

Fig. 1 で表わされる 1 入力 1 出力ルーリエ系 $S$ を考 える.すなわち，線形部は，

$$
\dot{x}=A(p) x+b(p) u, \quad y=c(p) x
$$

で与えられ，非線形部は，

$$
u=\varphi(e), \quad e=r-y
$$

で与えられるとする. ここに, $x \in \boldsymbol{R}^{n}, u \in \boldsymbol{R}, y \in \boldsymbol{R}$ は，それぞれ線形部の状態，入力，出力であり， $e \in \boldsymbol{R}$ は制御偏差である. $r \in \boldsymbol{R}$ は参照入力で, その值を閉 区間 $\mathscr{R}=[\underline{r}, \bar{r}](\underline{r} \leq 0 \leq \bar{r})$ にとる定数で，公称值を 0 とする. $p$ はパラメータで, その変動領域は有界閉領 域 $\mathscr{P} \subset \boldsymbol{R}^{l}$ 亡し, 公称値を $p^{*}$ で表わす。 また, $A(p)$, $b(p), c(p)$ はパラメータ $p \in \mathscr{P}$ の連続関数を成分上す る行列で, すべての $p \in \mathscr{P}$ に対して, $A(p)$ は安定で あるとする.

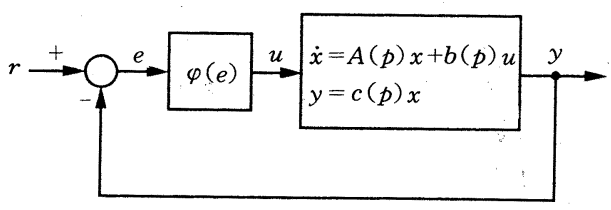

Fig. 1 Lur'e system

非線形関数 $\varphi: R \rightarrow \boldsymbol{R}$ は連続で, 原点の近傍 $E$ にお いて,

$$
\begin{aligned}
& 0 \leq \tilde{e}[\varphi(e+\tilde{e})-\varphi(e)] \leq k(e) \tilde{e}^{2}, \\
& \varphi(0)=0 \quad \forall e \in E, \forall \tilde{e} \in \boldsymbol{R}
\end{aligned}
$$

を満たすとする．乙こに, $k(e)$ は $e \in E$ によって決ま る正数である. ての仮定は, 点 $e \in E$ におけ $\varphi$ のセ ク夕条件であり, $\varphi(e)$ が原点近傍 $E$ において単調非減 少関数で, その傾きが有限であれば，適当な $k(e)$ につ いて満たされる. $\varphi(e)$ は, $E$ の外では, 減少関数であっ てもよい.

(11), (12) 式より, システム $S$ は,

$$
\begin{array}{r}
\mathcal{S}: \dot{x}=A(p) x+b(p) \varphi[r-c(p) x], \\
r \in \mathcal{R}, p \in \mathscr{P}
\end{array}
$$

と表わされる. 2.の例からあ明らかなように, このシス
テムでは, パラメータ $p$ のみらず, 参照入力 $r$ によっ て屯動特性が変化し得る. そてで, 以下では， $r, p$ の両 方をパラメータと考える.

$(r, p)$ が公称值 $\left(0, p^{*}\right) \in \mathscr{R} \times \mathscr{P}$ にあるとき, 公称 系

$$
\mathcal{S}^{*}: \dot{x}=A\left(p^{*}\right) x+b\left(p^{*}\right) \varphi\left[-c\left(p^{*}\right) x\right]
$$

の平衡状態は, 原点にある. したがって, 制御偏差 $e$ の 平衡点も原点である. そのため, 公称系 $\mathcal{S}^{*}$ では, 非線 形関数に対するセク夕条件として，(13）式で $e=0$ とお いた条件

$$
0 \leq \tilde{e} \varphi(\tilde{e}) \leq k(0) \tilde{e}^{2}, \forall \tilde{e} \in \boldsymbol{R}
$$

のみを考えて, システム $\mathcal{S}^{*}$ の絶対安定性が定義されて いる.すなわち, 平衡点である原点に抢けるセク夕条 件 (16) 式を満たす任意の非線形関数 $\varphi$ に対して, 原点 $x=0$ が大域漸近安定であるとき, 公称系 $\mathcal{S}^{*}$ はセク夕 $[0, k(0)]$ に対して絶対安定であるといわれる7).

しかし, 参照入力が $r \neq 0$ となった場合には, 2.の例 であ示したように, $r$ と $p$ の值によって平衡状態が変化 する. そして, 平衡状態が存在したとしてあ, それは原 点ではなくなる，そのため，乙の場合のシステム $S$ の 絶対安定性を考えるには，移動した平衡点に打けるセク 夕条件が非線形関数に対して必要である，そてで，本論 文では，原点を含むある閉区間 $E$ の各点におけるセク 夕条件 (13) 式を前提としている.

ここで, パラメータの変化に伴う平衡状態の変化を考 慮に入れた絶対安定性を定義しよう.

【定義】すべての $(r, p) \in \mathscr{R} \times \mathscr{P}$ と (13) 式を満たす 任意の非線形関数 $\varphi$ に対して, 平衡状態 $x^{e}(r, p)$ がた だ一つ存在し, それに対する制御偏差の平衡点 $e^{e}(r, p)$ が $E$ にあるする. 乙のとき、 $x^{e}(r, p)$ が大域漸近安 定であるならば, ルーリエ系 $\mathcal{S}$ はパラメトリック絶対 安定であるという.

\section{4. 平衡点解析}

ルーリエ系 $S$ のパラメトリック絶対安定性を示すた めには，まず，すべてのパラメータ $(r, p) \in \mathscr{R} \times \mathscr{P}$ と (13) 式のセク夕条件を満たすすべての非線形関数 $\varphi$ に 対して, 平衡状態が存在するための条件を与える必要が ある. 平衡状態が存在して, それが大域漸近安定である ならば，その平衡状態はただ一つであるといえるから， ここでは, 平衡状態の存在性についてのみ考察し, その 一意性は 5. の安定解析の結果によって保証する.

(14) 式で, $\dot{x}=0$ と置くことにより, システム $S$ の 平衡状態は

$$
A(p) x+b(p) \varphi[r-c(p) x]=0
$$


の解として得られる.（17）式は,

$$
x+A^{-1}(p) b(p) \varphi[r-c(p) x]=0
$$

と等価であり, また, 次式であ表わされる.

$$
\begin{aligned}
& x+A^{-1}(p) b(p) \varphi(e)=0 \\
& e=r-c(p) x
\end{aligned}
$$

乙の第 1 式を第 2 式に代入すると, 代数方程式

$$
e-r-c(p) A^{-1}(p) b(p) \varphi(e)=0
$$

が得られる.したがって，(19）式より，(20) 式の解 $e=e^{e}(r, p)$ の存在性之, (17) 式の解 $x=x^{e}(r, p)$ の 存在性が等価であることがわかる。乙れより，平衡状態 $x^{e}(r, p)$ の存在性に関する議論は, $e^{e}(r, p)$ の存在性 に関する議論で置き換えられる. しかも, 安定解析では, 非線形関数 $\varphi$ のセクタの上限を求めるために $e^{e}(r, p)$ の存在領域が必要である. そてで, (20) 式の解 $e=$ $e^{e}(r, p)$ が存在するための条件とその存在領域を与え よう.

【補題】条件

$$
\frac{1}{k(0)}-c(p) A^{-1}(p) b(p)>0, \quad \forall p \in \mathscr{P}
$$

が成り立つならば, 任意の $(r, p) \in \mathscr{R} \times \mathscr{P}$ 之 (13) 式の セク夕条件を満たすすべての非線形関数 $\varphi$ に対して, (20) 式の解 $e^{e}(r, p)$ が区間

$$
\begin{aligned}
& E^{e}(r, p) \\
& = \begin{cases}{\left[\frac{r}{\sigma_{0}(p)}, r\right],} & r\left\{c(p) A^{-1}(p) b(p)\right\} \leq 0 \text { のとき } \\
{\left[r, \frac{r}{\sigma_{0} \cdot(p)}\right],} & r\left\{c(p) A^{-1}(p) b(p)\right\}>0 \text { のとき }\end{cases}
\end{aligned}
$$

に存在する. こてに，

$$
\sigma_{0}(p)=1-c(p) A^{-1}(p) b(p) k(0)
$$

である.

ての補題の証明は以下のように示すてとができる. 関 数 $\phi(\cdot, p)$ を

$$
\phi(e, p)=e^{-c}(p) A^{-1}(p) b(p) \varphi(e), \forall e \in \boldsymbol{R}
$$

で定義すると，(13）式の原点に打ける条件 (16) 式より, $c(p) A^{-1}(p) b(p) \leq 0$ の場合は, 七ク夕条件

$$
e^{2} \leq e \psi(e, p) \leq \sigma_{0}(p) e^{2}, \forall e \in \boldsymbol{R}
$$

が, $c(p) A^{-1}(p) b(p)>0$ の場合は,

$$
\sigma_{0}(p) e^{2} \leq e \psi(e, p) \leq e^{2}, \forall e \in \boldsymbol{R}
$$

が成立する. Fig. 2 は，乙の条件を $r \geq 0$ の場合につ いて示したあのである. この図に扔いて，(20）式の解

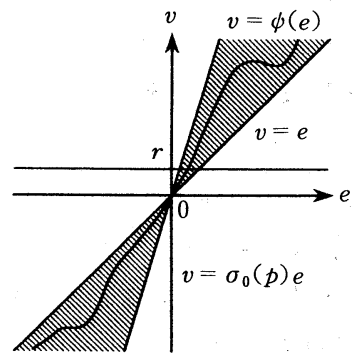

(a) $c(p) A^{-1}(p) b(p) \leq 0$

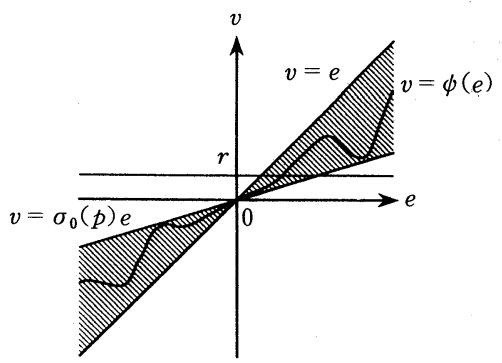

(b) $c(p) A^{-1}(p) b(p)>0$

Fig. 2 Sector condition on $\phi$

は, $v=\phi(e, p)$ のグラフと直線 $v=r$ との交点の $e^{-}$ 座標となる. Fig.2 (a) の場合は, すべての連続関数 $\phi(\cdot, p)$ に対して, 明らかに，そのような交点が存在す る. Fig. $2(\mathrm{~b})$ の場合は， $\sigma_{0}(p)>0$ のとき，すなわ ち，(21）式が成り立つとき，存在することが分かる．さ らに，乙れらの図より，(21）式のあとでの (20) 式の解 の存在区間が (22) 式で与えられるととが分かるのであ る.

補題の仮定のむとで，(13）式のセク夕条件を満たすす べての $\varphi$ に対する $e^{e}(r, p)$ の存在区間 $E^{e}(r, p)$ が分 かる．乙れより，(19）式の第1 式を用いれば，平衡状態 $x^{e}(r, p)$ の存在領域む求めることが可能である. しか し, 上で述べたように, 安定解析に必要なのは $e^{e}(r, p)$ の存在領域であって, $x^{e}(r, p)$ の存在領域は必要とし ない. 平衡状態 $x^{e}(r, p)$ については, その存在のみが 必要であり, それは, 上述の議論より, (21) 式の条件に よって保証されている.

\section{5. 安定条件}

ここでは, まず, 平衡状態 $x^{e}(r, p)$ が存在するとき, それが大域漸近安定となるための条件を述べる。 そして, 補題の条件を考慮し, システムS がパラメトリック絶 対安定であるための条件を与える.

システム $\mathcal{S}$ は, 平衡状態加ら偏差 $\tilde{x}=x-x^{e}(r, p)$ を用いると，つぎの偏差系 $\tilde{S}$ で表わされる.

$\tilde{\mathcal{S}}: \dot{\tilde{x}}=A(p) \tilde{x}+b(p) \tilde{\varphi}[-c(p) \tilde{x}]$ 
とてに

$$
\begin{aligned}
\tilde{\varphi}[-c(p) \tilde{x}]= & \varphi\left[-c(p) \tilde{x}+e^{e}(r, p)\right] \\
& -\varphi\left[e^{e}(r, p)\right] \\
e^{e}(r, p)= & r-c(p) x^{e}(r, p)
\end{aligned}
$$

である. ての $\tilde{\mathcal{S}}$ あルーリエ系であり，その平衡状態は $\tilde{x}=0$ である. そして, $\tilde{e}=e-e^{e}(r, p)$ とおくと, $e^{e}(r, p) \in E$ であるならば，(13）式より，

$$
0 \leq \tilde{e} \tilde{\varphi}(\tilde{e}) \leq k\left(e^{e}(r, p)\right) \tilde{e}^{2}, \quad \forall \tilde{e} \in \boldsymbol{R}
$$

が成り立つ。

さて,ルーリエ系に対するポポつの安定条件 ${ }^{7)} よ り ，$ （29）式の屯とで,

$$
\begin{array}{r}
\frac{1}{k\left(e^{e}(r, p)\right)}+\operatorname{Re}[\{1+j \omega \nu(r, p)\} g(j \omega, p)]>0, \\
\forall \omega \in \overline{\boldsymbol{R}}_{+}
\end{array}
$$

を満たす実数 $\nu(r, p)$ が存在するならば, $\tilde{\mathcal{S}}$ の平衡状 態 $\tilde{x}=0$ は大域漸近安定である. こてに, $g(s, p)$ は,

$$
g(s, p)=c(p)[s I-A(p)]^{-1} b(p)
$$

であり,ルーリエ系 $\mathcal{S}$ の線形部の伝達関数である。し たがって，すべての $(r, p) \in \mathscr{R} \times \mathscr{P}$ 亿対して (30) 式が 成り立てば, あとのルーリエ系 $\mathcal{S}$ の平衡状態 $x^{e}(r, p)$ の大域漸近安定性が示される.

しかし, (30) 式の条件中の $k\left(e^{e}(r, p)\right)$ は, 知ること のできない平衡点 $e^{e}(r, p)$ 亿依存しているので，その まま確かめることは不可能である. そこで, 補題で与え られる $e^{e}(r, p)$ の存在区間 $E^{e}(r, p)$ 加決まる

$$
k_{e}(r, p)=\max \left\{k(e): e \in E^{e}(r, p)\right\}
$$

を $k\left(e^{e}(r, p)\right)$ の代わりに用いることにする. すなわ ち,

$$
\begin{array}{r}
\frac{1}{k_{e}(r, p)}+\operatorname{Re}[\{1+j \omega \nu(r, p)\} g(j \omega, p)]>0, \\
\forall \omega \in \overline{\boldsymbol{R}}_{+}
\end{array}
$$

を満たす実数 $\nu(r, p)$ の存在を安定条件とすることがで きる.

ここで,

$$
k_{\mathscr{R}}(p)=\max \left\{k_{e}(r, p): r \in \Omega\right\}
$$

と怙き，pを固定して考えれば，つぎのてとが容易に分 かる. すなおち, $\nu(r, p)$ がすべての $r \in R$ 亿ついて存 在するためには，(33) 式で, $k_{e}(r, p)$ を $k_{\mathscr{R}}(p)$ で置 き換えて, $r$ 亿独立な実数 $\nu_{0}(p)$ が存在するてとが必要 十分である. なお, Fig. 2 から分かるように, 補題の仮 定のあとで，すべての $r \in \mathscr{R}$ に対する平衡点 $e^{e}(r, p)$ の存在区間は,

$$
\begin{aligned}
& E_{Q}^{e}(p) \\
& = \begin{cases}{[\underline{r}, \bar{r}],} & c(p) A^{-1}(p) b(p) \leq 0 \text { のとき } \\
{\left[\frac{\underline{r}}{\sigma_{0}(p)}, \frac{\bar{r}}{\sigma_{0}(p)}\right],} & c(p) A^{-1}(p) b(p)>0 \text { のとき }\end{cases}
\end{aligned}
$$

で与えられる. したがって，(34) 式の $k_{\mathscr{R}}(p)$ は，

$$
k_{\mathscr{Q}}(p)=\max \left\{k(e): e \in E_{\mathscr{Q}}^{e}(p)\right\}
$$

を用いて計算するてとができる.

以上より，パラメトリック絶対安定性のための定理を 得る.

【定理】（21）式の条件のむとで，与えられた参照入力 $r$ の範囲 $\mathscr{R}$ とすべての $p \in \mathscr{P}$ に対して,

$$
E_{\mathscr{R}}^{e}(p) \subset E
$$

が成り立ち，

$$
\begin{array}{r}
\frac{1}{k_{\mathscr{R}}(p)}+\operatorname{Re}\left[\left\{1+j \omega \nu_{0}(p)\right\}\right. \\
g(j \omega, p)]>0, \\
\forall \omega \in \overline{\boldsymbol{R}}_{+}
\end{array}
$$

を満たす実数 $\nu_{0}(p)$ が存在するならば，ルーリエ系 $\mathcal{S}$ はパラメトリック絶対安定である.

(23) 式の $\sigma_{0}(p)$ の定義と (35) 式より, $R \subset E_{\Re}^{e}(p)$ が成り立っている。したがって, 定理の (37) 式の条件 が成り立つためには， $R \subset E$ が必要である。乙れは， パラメトリック絶対安定性の解析のためには, 非線形部 の特性を表わすセク夕条件が, 少なくとも参照入力の範 囲で与えられている必要があるてとを意味している.

(38) 式の条件で $\omega=0$ と扔いて, $k(0) \leq k_{\mathscr{R}}(p)$ を 用いれば, 補題の (21) 式の条件を得る. 乙れより, 定 理では，(21）式の仮定が不要であるかのように見える. しかし，(38）式中の $k_{\Re}(p)$ を求めるために必要な区間 $E_{\mathscr{Q}}^{e}(p)$ は，(21) 式の条件のもとで与えられるから，補 題の条件をまず仮定せねばならない。

とてろで，一般には，すべての $p \in \mathscr{P}$ に対して線形 部の定常ゲインが正，すなわち， $g(0, p)>0$ である 場合が多い. 乙の場合には, $c(p) A^{-1}(p) b(p)<0$ で あるから, 補題の仮定は満たされ, 平衡点 $e^{e}(r, p)$ は 常に存在する，そして，(35）式より，その存在区間は $E_{\mathscr{R}}^{e}(p)=\Omega$ であり,(36) 式の $k_{\mathscr{R}}(p)$ は $p$ に依らない 定数

$$
k_{\mathscr{R}}(p)=k_{\mathscr{R}}^{*}=\max \{k(e): e \in \mathscr{R}\}
$$

となる、したがって, この場合の安定条件は, 以下のよ うになる。

【系】 $\mathscr{R} \subset E$ であるとする，すべての $p \in \mathscr{P}$ に対し て, $g(0, p)>0$ が成り立ち, 


$$
\begin{array}{r}
\frac{1}{k_{\mathscr{R}}^{*}}+\operatorname{Re}\left[\left\{1+j \omega \nu_{0}(p)\right\} g(j \omega, p)\right]>0, \\
\forall \omega \in \overline{\boldsymbol{R}}_{+}
\end{array}
$$

を満たす実数 $\nu_{0}(p)$ が存在するならば，ルーリエ系 $S$ はパラメトリック絶対安定である.

\section{6. 数 值 例}

5.の結果を用いて，与えられたルーリエ系のパラメト リック絶対安定性を確かめるには，すべてのパラメータ $p \in \mathscr{P}$ に対して，(38）式，または，(40) 式を満たす実 数 $\nu_{0}(p)$ の存在を調べる必要がある. しかし, 無限個 のパラメータ $p \in \mathscr{P}$ でとに実数 $\nu_{0}(p)$ の存在を示すの は，一般に困難である. そこで，代わりに，すべての $p \in \mathscr{P}$ に共通の実数 $\nu_{0}$ の存在を示すことを考える. そ うすれば，条件は保守的なもの之なるが，参考文献 4)， 5)，8）などの結果を用いて，ポポフ軌跡によって確かめ ることができる. 以下に，例を示そう.

【例 1】 Fig.1 で表わされるルーリエ系に掞いて, 線 形部の係数行列が,

$$
\begin{aligned}
& A(p)= {\left[\begin{array}{cc}
0 \\
0 \\
-p_{1}\left(0.2 p_{2}+p_{3}\right) & -p_{1}\left(0.5 p_{2}+p_{4}+0.2\right) \\
0 \\
1 \\
-0.5 p_{1}-p_{2}
\end{array}\right] } \\
& b(p)=b=\left[\begin{array}{l}
0 \\
0 \\
1
\end{array}\right], \quad c(p)=\left[\begin{array}{lll}
p_{1} p_{2} & p_{1} & 0
\end{array}\right]
\end{aligned}
$$

で与えられているとする. 参照入力 $r$ は区間 $R=$ $[-1,1]$ 内の值をとり, その公称值は $r^{*}=0$ とする. また, パラメータ $p=\left[\begin{array}{llll}p_{1} & p_{2} & p_{3} & p_{4}\end{array}\right]^{\mathrm{T}}$ の変動領域 $\mathscr{P}$ は,

$$
\begin{aligned}
\mathscr{P}= & \left\{p=\left[\begin{array}{llll}
p_{1} & p_{2} & p_{3} & p_{4}
\end{array}\right]^{\mathrm{T}}: 0.83 \leq p_{1} \leq 1.25,\right. \\
& 2.4 \leq p_{2} \leq 3.6,0.32 \leq p_{3} \leq 0.48 \\
& \left.1.44 \leq p_{4} \leq 2.16\right\}
\end{aligned}
$$

であり, 公称値は, $p^{*}=\left[\begin{array}{llll}1 & 3 & 0.4 & 1.8\end{array}\right]^{\mathrm{T}}$ とする. この 領域において,

$$
\begin{aligned}
& p_{1}\left(0.2 p_{2}+p_{3}\right) \leq 1.5 \\
& p_{1}\left(0.5 p_{2}+p_{4}+0.2\right)>2.3 \\
& p_{2}+0.5 p_{1}>2.8
\end{aligned}
$$

であるから, $A(p)$ の特性多項式にフルビッツの安定判 別法を適用することにより，線形部の安定性がいえる. 線形部の伝達関数は,

$$
\begin{aligned}
& g(s, p) \\
& =\frac{p_{1}\left(s+p_{2}\right)}{s^{3}+\left(p_{2}+0.5 p_{1}\right) s^{2}+p_{1}\left(0.5 p_{2}+p_{4}+0.2\right) s} \\
& \quad \nearrow \frac{}{+p_{1}\left(0.2 p_{2}+p_{3}\right)}
\end{aligned}
$$

である. 非線形部の関数 $\varphi$ は, 閉区間 $E=[-1,1]$ と

$$
k(e)=\frac{588-576 e}{65-64 e}, \quad e \in E
$$

について，(13）式のセクタ条件を満たす連続なあのと する.

このシステムでは, $R=E=[-1,1]$ であり, $p_{3} / p_{2} \leq$ 0.2 より,

$$
g(0, p)=\frac{5}{1+\frac{5 p_{3}}{p_{2}}} \geq 2.5>0, \quad \forall p \in \mathscr{P}
$$

であるから，系を用いてパラメトリック絶対安定性を確 かめるてとができる，乙こでは，上で述べたように，系 の (40) 式を満たす実数 $\nu_{0}(p)$ の存在を調べる代わりに,

$$
\begin{array}{r}
\frac{1}{k_{\mathscr{R}}^{*}}+\operatorname{Re}\left[\left\{1+j \omega \nu_{0}\right\} g(j \omega, p)\right]>0, \\
\forall \omega \in \overline{\boldsymbol{R}}_{+}
\end{array}
$$

を満たすすべての $p \in \mathscr{P}$ に共通の実数 $\nu_{0}$ の存在を，ポ ポフ軌跡を用いて確かめよう. そのために, 参考文献 8) の多角形区間演算を用いて, 非負の $\omega$ について, すべて の $p \in \mathscr{P}$ に対するポポフ軌跡が存在する領域を覆う多 角形を描いたものを Fig. 3 に示す. いま,

$$
k_{\mathscr{R}}^{*}=\max \{k(e): e \in \mathscr{R}\}=12
$$

であるから，Fig. 3 亿打いて，多角形軌跡の左側に， $-1 / k_{\mathscr{R}}^{*}=-1 / 12 \approx-0.0833$ を通る直線を引くことがで きる.したがって，(46）式を満たす実数 $\nu_{0}$ が存在し, 系より，乙こで考えているルーリエ系はパラメトリック 絶対安定である.

例 1 では，(46）式を満たす実数 $\nu_{0}$ の存在を確かめる

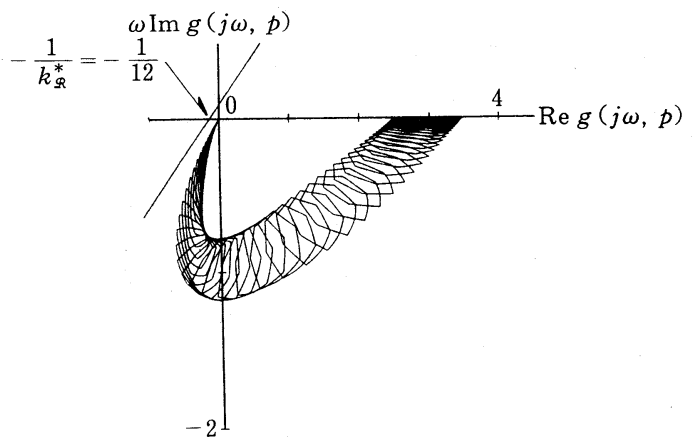

Fig. 3 Popov plot of Example 1 
ために，参考文献 8）の多角形区間演算を用いた。 ての 多角形区間演算を用いれば，すべての $p \in \mathscr{P}$ に対する ポポフ軌跡を覆うのに十分な多角形の軌跡を描くことが できる. そして, ての計算法は, 伝達関数 $g(s, p)$ の分 母子がそれぞれパラメータの成分の多重線形関数で, パ ラメータの各成分の変動区間が有界閉区間である場合に 適用できる.

乙の特殊な場合である，伝達関数 $g(s, p)$ の分母子 が，それぞれ区間多項式で表わされる場合には，参考文 献 4),5）の結果が適用できる. てれらの結果によると, （46）式を満たすすべての $p \in \mathscr{P}$ に共通の実数 $\nu_{0}$ の存 在性と，(46）式を満たすある 16 組のパラメータ $p$ 亿共 通の実数 $\nu_{0}$ の存在性とが必要かつ十分である. そてで, つぎに，そのような例を示そう.

【例 2】 Fig.1 で表わされるルーリエ系に扔いて, 線 形部の係数行列が,

$$
\begin{aligned}
& A(p)=\left[\begin{array}{ccc}
0 & 1 & 0 \\
0 & 0 & 1 \\
-1 & -p_{1} & -3.5
\end{array}\right], \quad b(p)=b=\left[\begin{array}{c}
0 \\
0 \\
0.5
\end{array}\right] \\
& c(p)=\left[\begin{array}{lll}
p_{2} & 0 & 0
\end{array}\right]
\end{aligned}
$$

で与えられているとする. 参照入力 $r$ の変動区間は $\mathscr{R}=[-0.5,0.5]$ であり, 公称值は $r^{*}=0$ とする. ま た, パラメータ $p=\left[\begin{array}{ll}p_{1} & p_{2}\end{array}\right]^{\mathrm{T}}$ の変動領域 $\mathscr{P}$ は,

$$
\mathscr{P}=\left\{p=\left[\begin{array}{ll}
p_{1} & p_{2}
\end{array}\right]^{\mathrm{T}}: 3 \leq p_{1} \leq 4,1 \leq p_{2} \leq 2\right\}
$$

を満たし, 公称值は, $p^{*}=\left[\begin{array}{ll}3.5 & 1.5\end{array}\right]^{\mathrm{T}}$ であるとする. 乙のとき, 線形部の伝達関数は,

$$
g(s, p)=\frac{0.5 p_{2}}{s^{3}+3.5 s^{2}+p_{1} s+1}
$$

であるから，線形部は安定である. 非線形部は，例 1 と 同じものとする.

$$
\begin{gathered}
\text { いま, } \mathscr{R}=[-0.5,0.5] \subset E \text { であり, } \\
g(0, p)=0.5 p_{2} \geq 0.5, \quad \forall p \in \mathscr{P}
\end{gathered}
$$

であるから，乙の例においても，系を用いるてとができ る. 例 1 と同様に, (40) 式を満たす実数 $\nu_{0}(p)$ の存在を 調べる代わりに，(46）式を満たすすべての $p \in \mathscr{P}$ に共 通の実数 $\nu_{0}$ の存在を確かめる. 参考文献 4), 5) の結果 によると, このような $\nu_{0}$ が存在するための必要十分条 件は,

$$
p=\left[\begin{array}{ll}
-4 & 1
\end{array}\right]^{\mathrm{T}},\left[\begin{array}{ll}
-4 & 2
\end{array}\right]^{\mathrm{T}},\left[\begin{array}{ll}
-3 & 1
\end{array}\right]^{\mathrm{T}},\left[\begin{array}{ll}
-3 & 2
\end{array}\right]^{\mathrm{T}}
$$

なる4 組のパラメー夕値に対して，(46) 式を満たす共通 の実数 $\nu_{0}$ が存在することである. てのパラメータの組

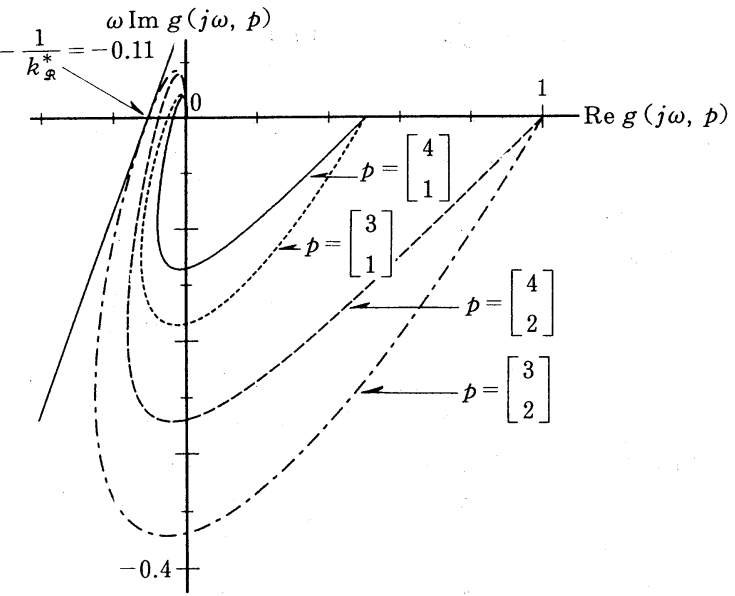

Fig. 4 Popov plot of Example 2

は，一般には 16 組であるが，乙てではパラメータ $p$ の 成分が 2 個であるので，(52）式のように4 組となった. (52) 式の 4 組のパラメータ值に対する線形部のポポフ 軌跡を Fig. 4 亿示す. いま,

$$
k_{\mathscr{R}}^{*}=\max \{k(e): e \in \Re\}=\frac{100}{11}
$$

であるから，実軸上の $-1 / k_{q}^{*}=-0.11$ を通り，ての四 つのポポフ軌跡を右にみる直線が引ける. したがって,

（46）式を満たす実数 $\nu_{0}$ が存在し，てのルーリエ系むパ ラメトリック絶対安定である.

\section{7. おわりに}

線形部に不確かなパラメータを含む 1 入力 1 出力ルー リエ系に対して, パラメータ変動に伴う平衡状態の変化 を考慮に入れた，パラメトリック絶対安定性という概念 を定義した. そして，そのための十分条件を，パラメー 夕を含むポポフ条件の形で導出した. その判定は, ポポ フ軌跡を用いて実行可能である.

線形部に定值外乱が加わる場合にあ，平衡状態は変化 する. 乙の場合についてあ，同様に議論ができ，本論文 の結果を容易に拡張するてとができる.

ルーリエ系が多入力多出力の場合も, 同様に, パラメ トリック絶対安定性のためのポポフ型の条件を得ること ができる. しかし, パラメータを含む多変数ポポフ条件 の判定は容易でない，したがって, 多変数ルーリエ系に 対しては別のアプローチが望まれる.

\section{参 考 文 献}

1) D. D. Šiljak : Nonlinear Systems, The Parameter Analysis and Design, Wiley (1969)

2) D. D. Šiljak : Polytopes of Nonnegative Polynomials ; 
Proc. ACC, pp. 193 199 (1989)

3) A. Tesi and A. Vicino : Robust Absolute Stability of Lur'e Control Systems in Parameter Space ; Automatica, Vol. 27, No. 1, pp. 147 151 (1991)

4) M. Dahleh, A. Tesi and A. Vicino: On the Robust Popov Criterion for Interval Lur'e Systems ; Proc. 31st Conf. Decision and Contr., pp. 2808 2809 (1992)

5）西村, 森, 黒江, 小亀：区間プラントを含むルーリエ系に 対するポポフの定理の適用について; システム制御情報学 会論文誌, Vol. 6, No. 4, pp.165１70 (1993)

6) M. Ikeda, Y. Ohta and D. D. Šljak (G. Conte, A. M. Perdon and B. Wyman (eds.)) : Parametric Stability; New Trends in Systems Theory, Birkhäuser pp. 1 20 (1991)

7) M. A. Aizerman and F. R. Gantmacher: Absolute Stability of Regulator Systems, (English Translation by E. Polak), Holden-Day (1964)

8) Y. Ohta, L. Gong and H. Haneda: Polygon Interval Arithmetic and Design of Robust Control Systems; Proc. 29th Conf. Decision and Contr., pp. 1065 1067 (1990) 